\title{
Responses of plasma glucose and nonesterified fatty acids to intravenous insulin tolerance tests in dairy cows during a 670-day lactation
}

\author{
L. C. Marett, ${ }^{* 1}$ M. J. Auldist, ${ }^{*}$ W. J. Wales, ${ }^{*}$ K. L. Macmillan, † F. R. Dunshea, $\ddagger$ and B. J. Leury \\ *Agriculture Victoria, Department of Economic Development, Jobs, Transport and Resources, Ellinbank, Victoria 3821, Australia \\ †Faculty of Veterinary and Agricultural Science, The University of Melbourne, Werribee, Victoria 3030, Australia \\ ‡Faculty of Veterinary and Agricultural Science, The University of Melbourne, Parkville, Victoria 3010, Australia
}

\begin{abstract}
The metabolic response of dairy cows undergoing an extended lactation to an insulin tolerance test (ITT) was investigated. Twelve multiparous Holstein-Friesian cows that calved in late winter in a pasture-based system were managed for a 670 -d lactation by delaying rebreeding. Four 5-wk experimental periods commenced at approximately $73,217,422$, and $520 \mathrm{~d}$ in milk (DIM). Cows were offered a diet of perennial ryegrass (73 and 422 DIM) or pasture hay and silage (217 and 520 DIM) supplemented with $1 \mathrm{~kg}$ dry matter (DM) of grain (control; CON) or $6 \mathrm{~kg} \mathrm{DM}$ of grain (GRN). Daily energy intake was approximately 160 and 215 MJ of metabolizable energy/cow for CON and GRN, respectively. At all other times, cows were managed as a single herd and grazed pasture supplemented with grain to an estimated daily intake of $180 \mathrm{MJ}$ of metabolizable energy/cow. Cows were fitted with a jugular catheter during the final week of each experimental period. An ITT using $0.12 \mathrm{IU}$ of insulin $/ \mathrm{kg}$ of body weight (BW) was conducted on each cow at approximately 100, 250, 460, and 560 DIM. Cows in the GRN treatment had greater milk yield, milk solids yield, and BW than cows in the CON treatment. Within treatment, individual cow responses to the ITT were highly variable. Plasma glucose and nonesterified fatty acid (NEFA) concentrations declined at all stages of lactation. The clearance rate of plasma glucose was slower before 300 DIM than after 300 DIM, which indicates greater inhibition of hepatic glucose synthesis and uptake of glucose by insulin-dependent tissues later in the lactation. The clearance rate, area under the curve, and recovery of plasma NEFA were greatest at 100 DIM, indicating greater responsiveness to the antilipolytic effect of insulin in early lactation, but also greater lipolytic responsiveness. The variation in response to the ITT was mostly a result of DIM rather than diet. However, the
\end{abstract}

Received September 12, 2016.

Accepted November 26, 2016.

${ }^{1}$ Corresponding author: leah.marett@ecodev.vic.gov.au plasma NEFA response showed interactions between diet and DIM, indicating that energy intake may affect tissue responses to insulin. The responsiveness of peripheral tissues to insulin, primarily adipose tissue, changed throughout a 670-d lactation and contributed to a greater proportion of nutrients being partitioned to body reserves at the expense of milk yield as lactation progressed. Both stage of lactation and dietary intake have a role in the determination of whole-body and peripheral tissue responses to insulin; however, the exact mechanisms in control of this are unclear.

Key words: extended lactation, insulin sensitivity, fatty acid metabolism, nutrient partitioning

\section{INTRODUCTION}

There is large variation in the capacity of cows to undergo extended lactations of up to $670 \mathrm{~d}$ in the pasture-based dairying systems of Australia (Auldist et al., 2007; Grainger et al., 2009) and New Zealand (Kolver et al., 2007). Some of this may be due to differences in physiological characteristics of cows, leading to variation in the regulation of nutrient partitioning. In previous experiments, cows that were unable to complete a 670-d lactation gained more BW and BCS than those able to continue milking. Those cows that successfully completed an extended lactation also had higher plasma concentrations of growth hormone and nonesterified fatty acids (NEFA), but lower concentrations of insulin, glucose, and leptin beyond 300 DIM (Delany et al., 2010; Marett et al., 2011). It has been shown that grazing cows with either restricted or unrestricted feed intakes had similar lactational persistency during extended lactations (Grainger et al., 2009; Delany et al., 2010; Marett et al., 2011).

Insulin is a key regulator of glucose homeostasis in mammals, with blood concentrations shifting with changing physiological priorities of the body (Bauman and Currie, 1980). The actions of insulin are anabolic, promoting the storage of energy substrates, such as glucose and fatty acids (Blum et al., 1983), and inhibiting hepatic glucose production (Brockman and Laarveld, 
1986). Plasma insulin is decreased during times of increased energy requirements for milk production, supporting nutrient partitioning toward the mammary gland for milk production by decreasing the utilization of these nutrients by insulin-dependent tissues (Bauman and Currie, 1980). This occurs because the movement of glucose across the cell membrane for milk production in the mammary gland largely does not require insulin (Collier et al., 1984). Insulin resistance occurs before and after parturition in lactating goats (Debras et al., 1989), sheep (Prior and Christenson, 1978), and cows (Sano et al., 1993; Bell and Bauman, 1997; Vernon and Pond, 1997). Cows with high milk yield have a greater degree of insulin resistance than lower-yielding counterparts, regardless of whether the increased milk yield is due to treatment with recombinant somatotropin (Sechen et al., 1990) or simply genetic merit (Cronje, 2000; Chagas et al., 2009).

Insulin sensitivity, as well as glucose and fatty acid metabolism, have been studied intensively throughout the periparturient period and early lactation in dairy cows. However, there are few data beyond 300 DIM and even fewer in pasture-fed cows. Marett et al. (2015) reported that whole-body sensitivity to insulin following an intravenous glucose tolerance test (IVGTT) in dairy cows fed a pasture-based diet and undergoing a 670-d lactation was highly variable. Those authors showed, in response to an IVGTT, a reduction in responsiveness to insulin in terms of glucose clearance but an increase in the antilipolytic response to insulin at 4 stages of an extended lactation. This suggests that the regulation of insulin sensitivity and responsiveness during lactation may vary between insulin-responsive tissues in response to changing mammary gland requirements for milk production. Further, differences may exist in the proportions of the response that are related to either skeletal muscle or adipose tissue at any given stage of lactation or physiological state. Diet may also affect the dairy cow's response to insulin. Although Marett et al. (2015) showed that feeding a diet with a greater proportion of grain decreased whole-body responsiveness to insulin in terms of plasma glucose but not fatty acids response, Schoenberg et al. (2012) reported that insulin sensitivity was not affected by feed intake in nonlactating cows. Thus, it remains unclear whether feed or energy intake affects insulin sensitivity.

To adequately develop nutritional strategies for use during extended lactations, a better understanding of the regulation of nutrient partitioning is required. The insulin tolerance test (ITT) investigates the insulin responsiveness of insulin-dependent tissues, primarily adipose and skeletal muscle tissues (Kaneko, 1997). In these experiments, the ITT was conducted at 4 stages of a 670-d lactation to investigate insulin responsiveness in terms of plasma glucose and fatty acids responses. In particular, we aimed to investigate the response of peripheral tissues to exogenous insulin in terms of glucose clearance and the inhibition of lipolysis. These experiments aimed to identify sources of variation in metabolic responses to hyperinsulinemia in cows undergoing an extended lactation and determine whether the responses were affected by cereal grain intake. We hypothesized (1) that the estimated responsiveness to insulin, in terms of the glucose and fatty acids response to an exogenous insulin infusion, would increase with increasing DIM; and (2) that the dietary intake of cereal grain would not affect either the plasma glucose response or the plasma fatty acids response to the ITT.

\section{MATERIALS AND METHODS}

\section{Location}

This experiment was conducted at the Department of Economic Development, Jobs, Transport and Resources (DEDJTR) Ellinbank Centre in Victoria, Australia $\left(38^{\circ} 14^{\prime} \mathrm{S}, 145^{\circ} 56^{\prime} \mathrm{E}\right)$. All procedures were approved by the DEDJTR Animal Ethics Committee.

\section{Cows and Management}

The experimental design was described previously by Marett et al. (2015). Briefly, the experiment used 12 multiparous Holstein-Friesian cows of mixed age that calved in late July (winter). They were managed for an extended lactation by delaying breeding until $\sim 450$ DIM for a target lactation length of $670 \mathrm{~d}$. They were managed as a single herd for the majority of their lactations and grazed perennial ryegrass (Lolium perenne) pasture supplemented with cereal grain fed twice daily in the parlor at milking times. When pasture was limiting during the summer and autumn months, pasture hay (approximately $6 \mathrm{~kg}$ of DM/cow per day) and pasture silage (approximately $10 \mathrm{~kg}$ of $\mathrm{DM} /$ cow per day) were offered to achieve an estimated daily intake of 180 MJ of ME/cow.

There were 4 experimental periods of up to $40 \mathrm{~d}$ during these lactations, beginning at each of $\sim 73,217$, 422 , and $520( \pm 9.1)$ DIM (mean $\pm \mathrm{SD})$. Two treatments were used, designated control $(\mathbf{C O N})$ and grain (GRN), each allocated randomly to 6 cows. Treatment groups were balanced for parity, calving date, BW, and yields of milk, protein, and fat in the preceding lactation (Baird, 1994). During the experimental periods, CON cows were fed $1 \mathrm{~kg}$ (DM) of grain/d and GRN cows were fed $6 \mathrm{~kg}(\mathrm{DM})$ of grain/d, with half of the total daily grain allowance fed to individual cows at each milking. Forage and freshly cut pasture were fed 
twice daily in individual feed bins while cows were restrained in stalls. The targeted total ME intake was approximately 160 and $215 \mathrm{MJ} / \mathrm{cow}$ per day for the CON and GRN treatments, respectively. After they had eaten, cows were released from stalls to a loafing pad where they had ad libitum access to fresh water. They were milked twice daily at $\sim 0700$ and $1500 \mathrm{~h}$. Five days before the end of each experimental period, cows were relocated to metabolism stalls. Each cow was fitted with a harness and chute to remove feces and urine and was milked in place. The ITT were conducted during this time when cows were at $\sim 100,250,460$, and 560 DIM.

The dry-off threshold and breeding program were implemented as described previously by Auldist et al. (2007). Some cows were removed from the experiment because their milk yield fell below the dry-off threshold (30 kg/cow per week for 2 consecutive weeks) or because of unrelated health issues. During the course of the 4 experimental periods, $4 \mathrm{CON}$ and 2 GRN treatment cows were replaced with cows of comparable age, DIM, and milk yield.

Milk yield, nutrient intake, and BW were each measured as described in Marett et al. (2015). Milk yield and feed intake were measured twice daily; BW was measured at the start and end of the experiment.

\section{Insulin Tolerance Test}

Each cow was fitted with an indwelling jugular catheter under local anesthesia during the final week of each experimental period and then rested for $24 \mathrm{~h}$ before the first sampling. Samples of blood were then collected every $4 \mathrm{~h}$ over a 24 -h period. Insulin tolerance tests were performed on each cow within the following $3 \mathrm{~d}$. Cows had feed removed for $12 \mathrm{~h}$ before the ITT. Blood samples were collected at 20,10, and 1 min before administering an intravenous injection $(0.12 \mu \mathrm{U} /$ $\mathrm{kg}$ of BW) of human insulin (Actrapid, Novo Nordisk, Baulkham Hills, NSW, Australia). Additional samples were then collected every $5 \mathrm{~min}$ for $2 \mathrm{~h}$ and then at 150, 180, 210, and 240 min after insulin infusion, with each sample collected into a heparinized Vacutainer (BD Vacutainer Systems, Plymouth, UK) and immediately chilled on ice before being centrifuged at $1,800 \times g$ for $10 \mathrm{~min}$ at $4^{\circ} \mathrm{C}$ within $1 \mathrm{~h}$ of collection. Plasma was decanted and stored at $-20^{\circ} \mathrm{C}$ until analyzed for glucose and NEFA concentrations.

Plasma glucose concentrations $(\mathrm{m} M)$ were measured using a commercially available kit (Thermo Infinity Glucose Oxidase Liquid, Thermo Fisher, Noble Park, VIC, Australia). Plasma NEFA concentrations were measured using the commercially available Wako NEFA-C kit (Wako Chemicals USA, Richmond, VA) adapted for 96-well microplates (Johnson and Peters, 1993). Insulin in plasma was measured in duplicate by the double-antibody RIA method described by Tindal et al. (1978). Insulin anti-serum was raised in a guinea pig using bovine insulin (BI 4499, Eli Lilly Pty Ltd., Melrose Park, NSW, Australia). Cross-reactions were 100\% with bovine insulin (lot 016666; Novo Bio Labs, Danbury, CT). Every sample was assayed in duplicate. Intra- and inter-assay coefficients of variation were $<3 \%$ and $<5.5 \%$ for glucose, $<4 \%$ and $<6 \%$ for NEFA, and $<5 \%$ and $9 \%$ for insulin, respectively.

\section{Calculations and Statistical Analyses}

The trapezoidal method was used to calculate the area under the curve (AUC); in this case, the area below baseline and above the response curve for plasma glucose and NEFA. Clearance rates (CR) were expressed as the apparent fractional rate of change for a given period and were determined from the slope of the natural logarithm of the plasma concentration (glucose or NEFA) plotted against time. The change (reduction) in plasma glucose and NEFA were calculated as the difference between basal concentration and the nadir as a percentage of the basal concentration.

Data were analyzed for differences in response measures at each of the 4 stages of the lactation (100, 250, 460 , and 560 DIM) and between dietary treatments using a mixed model with REML analysis (GenStat11.0; VSN International Ltd., Hemel Hempstead, UK). The model included fixed effects for DIM and diet, with the cow as the random effect. For the 24-h sampling, the average of the plasma glucose or insulin concentration of the 7 samples collected was used. For each plasma glucose or NEFA parameter for the ITT, basal values were calculated by taking the average of the 3 samples before insulin infusion. Recovery values were calculated as the average of the final 3 samples. Skewed data for the NEFA AUC were analyzed after $\log _{10}$ transformation to normalize the variance. Conclusions made from this analysis were similar to those from the analysis of the back-transformed data. The back-transformed data are presented in the tables.

\section{RESULTS}

\section{Milk Yield and Feed Intake}

Milk yield, milk composition, DMI, ME intake, and BW were reported in detail by Marett et al. (2015) and are summarized in Table 1. Briefly, milk yield, milk solids yield, DMI, and ME intake decreased with increasing DIM $(P<0.001)$ and were greater in the GRN compared with the CON treatment $(P<0.001)$. Body 
weight increased with increasing DIM $(P<0.001)$ and tended to be greater in the GRN compared with the CON treatment $(P=0.057)$.

\section{Insulin Tolerance Test}

Data from the 24-h sampling and ITT are presented in Table 2 and Figures 1 and 2, presented as means \pm standard error of the difference. Plasma glucose concentration increased with increasing DIM $(3.4,3.4,3.5$, and $3.6 \pm 0.07 \mathrm{mM}$ at 100, 250, 460, and 560 DIM, respectively; $P=0.002$ ) for the 24 -h sampling (Figure 1 ), and plasma insulin concentration was also affected by $\operatorname{DIM}(3.6,3.7,5.7$, and $4.7 \pm 0.38 \mu \mathrm{U} / \mathrm{mL}$ at 100 , 250, 460 and 560 DIM, respectively; $P<0.001$ ), being lower before 300 DIM compared with 460 and 560 DIM. Further, plasma concentrations of glucose were greater in the GRN than the CON treatment (3.6 vs. $3.3 \pm$ $0.05 \mathrm{mM} ; P<0.001$ ), and plasma insulin concentration tended to be greater in the GRN treatment compared with the $\mathrm{CON}$ treatment (4.7 vs. $4.2 \pm 0.26 \mu \mathrm{U} / \mathrm{mL}$; $P=0.065)$.

Concentrations of glucose and NEFA were measured in all plasma samples taken during all 4 ITT (Table 2, Figure 2). Before the infusion of insulin, basal plasma glucose was not affected by DIM but tended to be greater in the GRN compared with CON treatment (3.7 vs. $3.5 \mathrm{~m} M \pm 0.10 ; P=0.063)$. There was a tendency $(P=0.072)$ for an interaction between diet and DIM (Table 2), such that basal plasma glucose concentration was greater in GRN cows at 100 DIM but greater in the CON treatment at 250 DIM.

Plasma concentrations of glucose declined in response to insulin infusion at all stages of lactation. They reached a nadir between 30 and 40 min after infusion of insulin and were reduced by more than $50 \%$ with no effect of DIM or diet on the percentage change. However, the minimum concentration of plasma glucose tended to be greater in the GRN than the CON treatment (1.6 vs. $1.5 \pm 0.07 \mathrm{mM} ; P=0.075$ ). The fractional rate of glucose clearance (CR 5-30 min) postinfusion was reduced at 250 DIM relative to that at 100, 460, and 560 DIM $(P=0.002)$. There was no effect of DIM or diet on any measure of glucose AUC. The recovery of plasma glucose concentration was affected by both DIM and diet, decreasing with increasing DIM (4.4, $3.9,3.9,3.8 \pm 0.16 \mathrm{~m} M$ at $100,250,460$, and $560 \mathrm{DIM}$, respectively; $P=0.010)$ and being greater in the GRN than CON treatment (4.1 vs. $3.9 \pm 0.11 \mathrm{~m} M ; P=$ $0.017)$. We detected a strong interaction $(P<0.001)$, such that plasma glucose concentration was greater in GRN cows than in CON cows at 100 and 460 DIM.

Basal plasma NEFA concentrations were affected by DIM, being greatest at 100 , intermediate for 460 ,

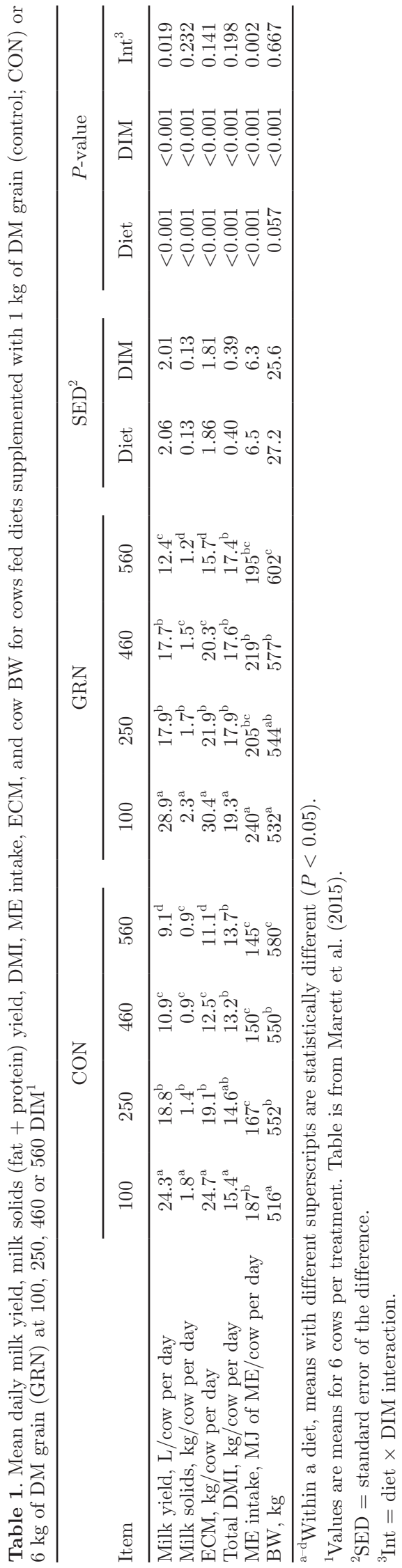

Journal of Dairy Science Vol. 100 No. 4, 2017 


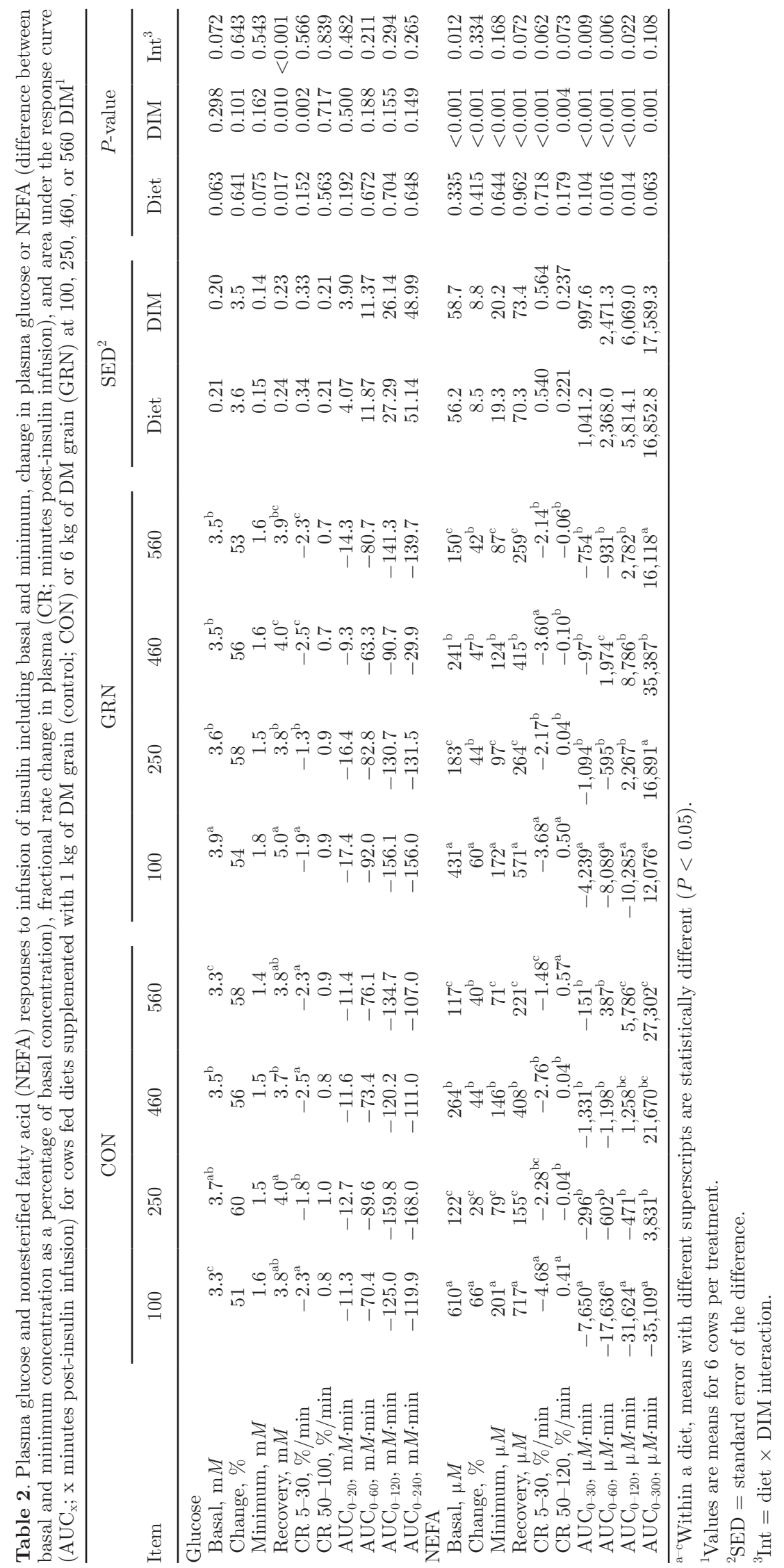



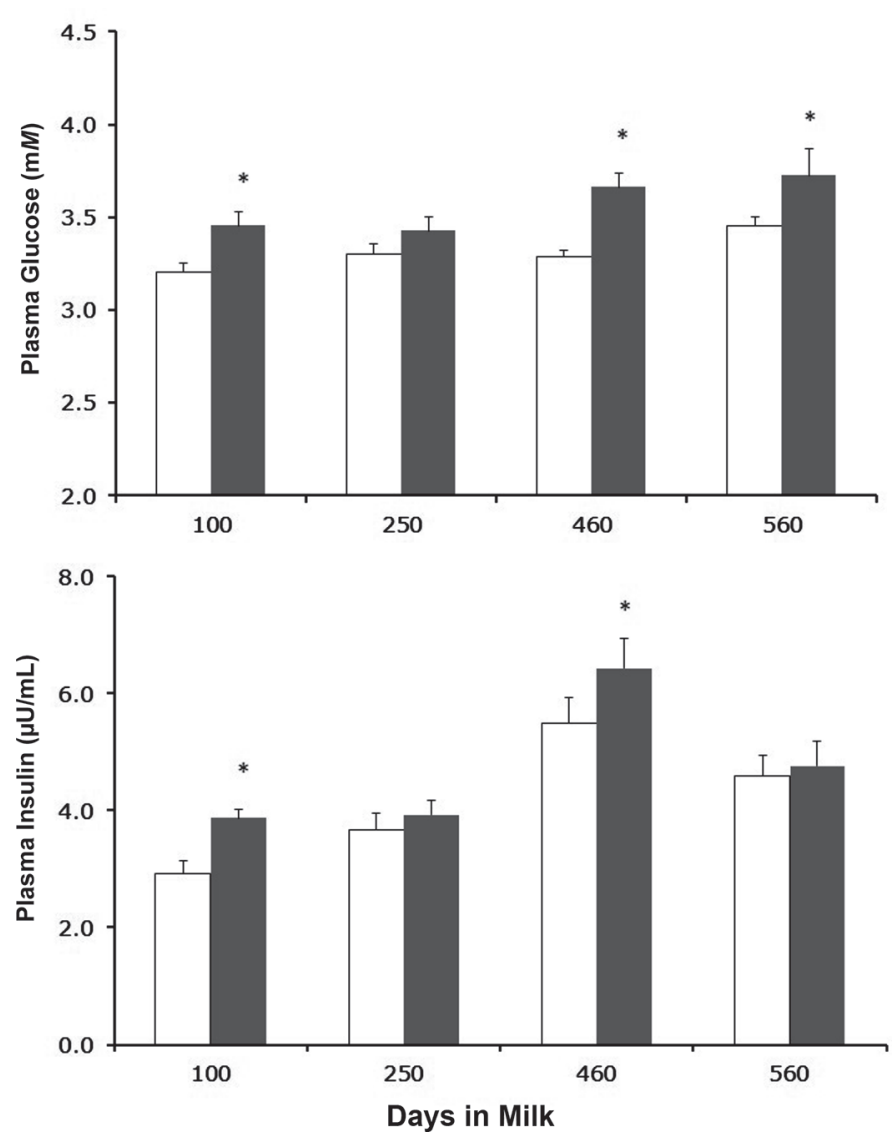

Figure 1. Mean plasma concentrations of 7 samples per cow over $24 \mathrm{~h}$ at each of 100, 250, 460, and 560 DIM for (a) glucose; and (b) insulin at 4 stages of an extended lactation in cows fed a diet supplemented with $1 \mathrm{~kg}$ of DM grain (CON; open bars) or $6 \mathrm{~kg}$ of DM grain (GRN; solid bars). Data are means of 6 cows per treatment, and error bars represent standard error of the mean. Asterisks represent differences between treatments $(P<0.05)$.

and lowest at 250 and 560 DIM $(520,152,253,133 \pm$ $39.7 \mu M$ at $100,250,460$, and 560 DIM, respectively; $P<0.001)$. Basal plasma NEFA concentrations were not affected by diet, but there was an interaction between DIM and diet $(P=0.012)$, as the basal NEFA concentrations were greater in CON cows at 100 DIM compared with GRN cows.

Plasma concentrations of NEFA declined in response to insulin infusion at all stages of lactation. The change in plasma NEFA was affected by DIM $(63,46,45$, and $41 \pm 6.0 \%$, at $100,250,460$, and 560 DIM, respectively; $P<0.001$ ), with the greatest change occurring at 100 DIM, being reduced by 66 and $60 \%$ in the CON and GRN treatments, respectively, whereas at 250, 460, and 560 DIM, plasma NEFA concentrations were only reduced by between 28 and $47 \%$. We detected no overall effect of diet on the change in plasma NEFA concentrations. Plasma NEFA concentrations reached a nadir at approximately 30 min post-infusion and the nadir was greatest at 100 , intermediate at 460 , and lowest at 250 and 560 DIM $(187,88,135,79 \pm 13.7 \mu M$ at 100,250 , 460 and 560 DIM, respectively; $P<0.001$ ). The CR of plasma NEFA 5-30 min post-infusion was clearly affected by DIM $(-4.2,-2.2,-3.2,-1.8 \pm 0.38 \% / \mathrm{min}$; $P<0.001)$ with no overall effect of diet. We detected a tendency for an interaction between diet and DIM $(P$ $=0.062)$ as the CON treatment had the fastest NEFA CR 5-30 min at 100 DIM, intermediate at 250 and 460 DIM, and lowest at 560 DIM, whereas the NEFA CR 5-30 min was fastest at 100 and 460 DIM and slower at 250 and 560 DIM in the GRN treatment. The rate of NEFA re-entry into the bloodstream (CR 50-120) was affected by DIM $(0.46,0.00,-0.03$, and $0.25 \pm 0.25 \%$ / min at 100, 250, 460, and $560 \mathrm{DIM}$, respectively; $P=$ 0.004 ) but not diet, and there tended to be an interaction between DIM and diet $(P=0.073)$. The NEFA CR 50-120 was greatest at 100 and 560 DIM in the CON treatment, whereas in the GRN treatment, it was only greater at 100 DIM. The plasma NEFA $\mathrm{AUC}_{0-30}$ postinfusion was greatest at 100 DIM compared with 250, 460, and 560 DIM $(-5,994,-695,388,-272$ $\mu M \cdot \min$ at $100,250,460$, and 560 DIM, respectively; $P$ $<0.001)$ but was not affected by diet. However, there was an interaction between DIM and $\operatorname{diet}(P=0.009)$ such that plasma NEFA $\mathrm{AUC}_{0-30}$ was greater in the CON treatment at 100 DIM but greater in the GRN treatment at 250 DIM. The cumulative plasma NEFA AUC $_{0-120}$ were affected by both DIM $(-20,955,898$, $5,022,4,284 \pm 4,109.2 \mu M \cdot \min$ at $100,250,460$, and 560 DIM, respectively; $P<0.001)$ and was greater in the GRN compared with the CON treatment (887 vs. $-6,263 \pm 2,911.4 \mu M \cdot \min ; P=0.014)$. The recovery plasma NEFA concentrations reflected basal plasma NEFA concentrations and were greatest at 100 DIM, intermediate at $460 \mathrm{DIM}$, and lowest at 250 and 560 DIM $(644,209,412$, and $240 \pm 49.7 \mu M$ at 100,250 , 460, and 560 DIM, respectively; $P<0.001$ ).

\section{DISCUSSION}

Reports of insulin sensitivity and responsiveness in dairy cows are generally limited to the nonlactating state (Pires et al., 2007; Sartin et al., 1985; Holtenius et al., 2003), the periparturient period, or traditional lactations of up to $305 \mathrm{~d}$ in length (Denbow et al., 1986; Chagas et al., 2003; Holtenius et al., 2003). Changes in response to insulin have been associated with the onset of lactation (Sartin et al., 1985), age (McClary et al., 1988), and obesity (Bergman et al., 1989). This is the first report of the ITT being used as a method to 

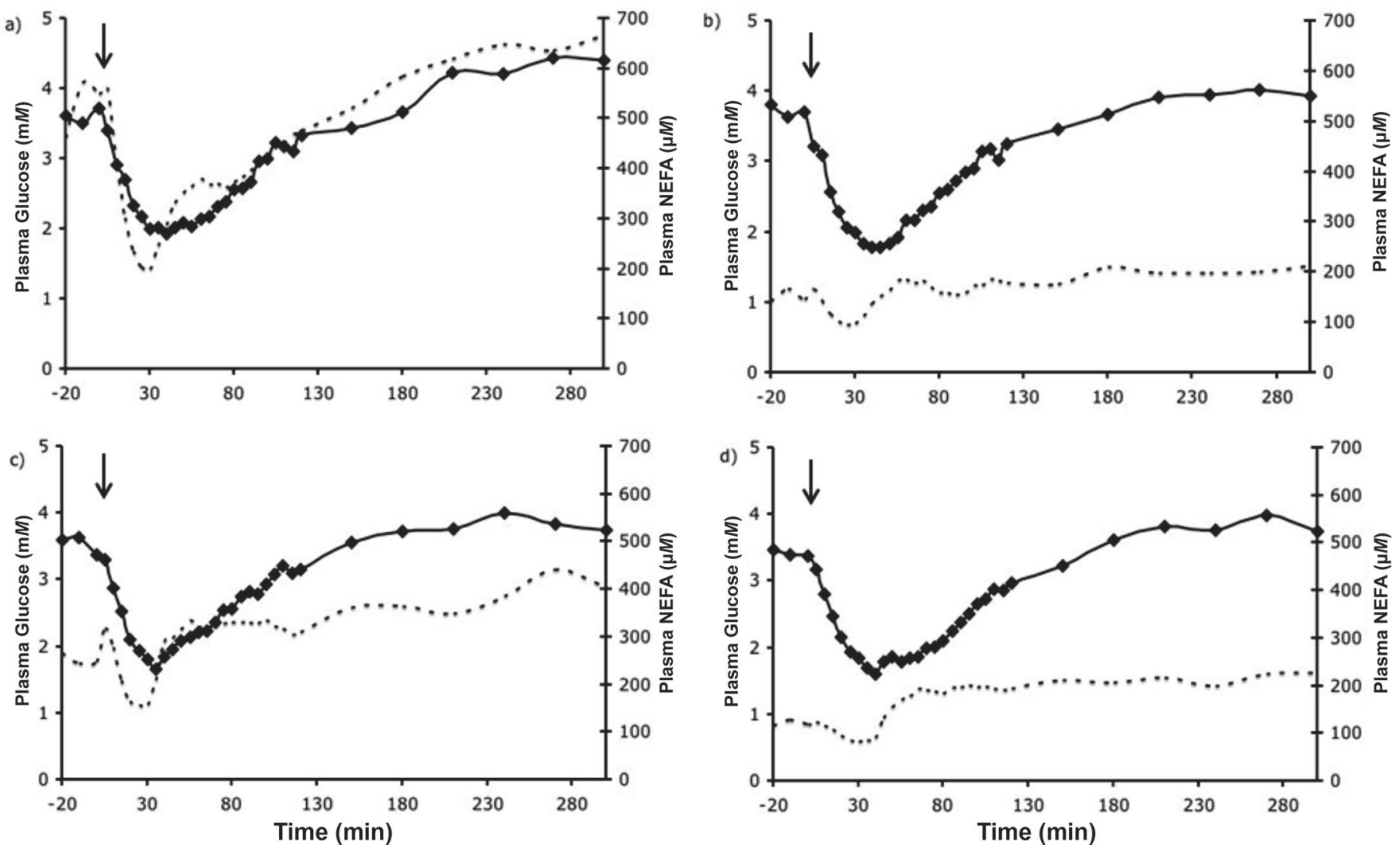

Figure 2. Plasma glucose $(\checkmark)$ and nonesterified fatty acid (NEFA; - - ) responses to insulin infusion $(0.12 \mu \mathrm{U} / \mathrm{kg}$ of BW) at time 0. Data are for challenges performed when cattle were at approximately (a) 100, (b) 250, (c) 460, and (d) 560 DIM. Arrows denote insulin infusion at time zero. Pooled standard errors for each stage of lactation were $0.27,0.23,0.24$, and 0.23 for glucose, and 64.7, 29.4, 45.1, and 24.3 for NEFA, respectively.

evaluate the metabolic response of dairy cows to insulin at several stages of an extended lactation.

We detected large variation in individual cow responses to the ITT at every stage of the extended lactation, both between treatments and within treatment. Thus, variation exists in the insulin sensitivity and glucose and fatty acid metabolism of cows at various stages of an extended lactation and these responses are influenced by dietary intake. Collectively, the current data and that presented by Marett et al. $(2014,2015)$ indicate that the greatest changes in responsiveness to insulin in dairy cows occur not in glucose metabolism but in the metabolism of fatty acids throughout an extended lactation. This is consistent with previous reports of differential responses of fatty acid and glucose metabolism to insulin in dry dairy cows (Schoenberg et al., 2012; De Koster et al., 2016). This may be due to a greater proportion of the demand for glucose placed by the insulin-independent mammary gland and the significant changes that occur in regard to fatty acid metabolism in support of milk yield throughout lactation.
The proportion of nutrients partitioned to body tissue gain at the expense of milk yield increases in both conventional (Ronge et al., 1988; Busato et al., 2002; Reist et al., 2002) and extended lactations (Sorensen and Knight, 2002; Delany et al., 2010; Marett et al., 2011). The milk production, BW, and plasma glucose and insulin concentration data collected in this experiment over $24 \mathrm{~h}$ at 4 stages of an extended lactation support this. The greater basal plasma NEFA concentrations (collected immediately before the ITT) throughout the first $300 \mathrm{~d}$ of the lactation indicate lower rates of lipolysis and possibly increased rates of lipogenesis beyond 300 DIM. The greater basal plasma glucose concentration in GRN compared with CON cows was consistent with their greater DMI, ME intake, and, therefore, propionate availability as a substrate for gluconeogenesis (Evans et al., 1975; Jenny and Polan, 1975; Dhiman et al., 1991). Although basal plasma glucose concentrations in this experiment did not increase with increasing DIM, as reported by Marett et al. (2011, 2015), recovery plasma glucose concentrations did follow the expected pattern and probably indicate 
declining uptake of systemic glucose by the mammary gland. These data support previous findings that dairy cows partition more nutrients toward tissue gain at the expense of milk production throughout the later period of an extended lactation (Sorensen and Knight, 2002; Delany et al., 2010; Marett et al., 2011).

Generally, insulin resistance in monogastric animals is identified if the blood glucose concentration does not fall to below $50 \%$ of basal blood glucose or if this occurs after 30 min post-infusion (Kaneko, 1997). By the definition of Kaneko (1997), insulin resistance was observed at all stages of lactation, with plasma glucose concentration reduced by more than $50 \%$ between 30 and 40 min after infusion of insulin. However, there is no threshold for insulin resistance per se in ruminants, which typically maintain lower basal concentrations of blood glucose than monogastric animals, particularly during lactation. Also, ruminants are considered to be less insulin sensitive than monogastrics (Dunshea and D'Souza, 2003). We observed few effects of stage of lactation on the plasma glucose response curve, but the glucose CR was slower before 300 DIM than after 300 DIM, indicating greater glucose clearance by insulindependent means in response to insulin infusion in the extended lactation phase. These data support the first hypothesis, are in agreement with the data of Marett et al. (2014), and show that, in terms of glucose metabolism, insulin sensitivity increased with increasing DIM.

The results of the current experiment showed a greater responsiveness to the antilipolytic effects of insulin as the extended lactation progressed. At 100 DIM, there was a greater reduction in plasma NEFA concentration $(<60 \%)$ compared with later stages $(460$ and $560 \mathrm{DIM})$ of the extended lactation $(<47 \%)$. Thus, at $100 \mathrm{DIM}$, the cows were more responsive to insulin in regard to clearance of NEFA from the blood, which includes both the processes of re-esterification of fatty acids and inhibition of lipolysis. Moreover, the relatively low basal plasma NEFA concentrations beyond 100 DIM suggest that mobilization of adipose tissue was much reduced as the lactation progressed. However, the actual measurement of the true rates of lipolysis and lipogenesis are more complicated than this. When adipose tissue is mobilized, triacylglycerol is broken down to NEFA, which are released into the bloodstream or immediately re-esterified, and glycerol, which is almost exclusively released into the circulation (Dunshea et al., 1990). Studies of glycerol and NEFA kinetics in goats have shown that the rate of intracellular re-esterification of fatty acids can change, leading to an under-estimation of the true rate of lipolysis during early lactation (Dunshea et al., 1990). Although there is no information available on glycerol kinetics during an extended lactation, the rates of lipolysis in the current experiment may be greater than expected using only the plasma NEFA concentration. Given the low plasma NEFA concentration measured after 300 DIM, and the concomitant increase in cow BW as lactation progressed, it is plausible that the rate of intracellular re-esterification of fatty acids was high. Thus, the rate of lipolysis in these cows in the extended phase of the lactation may also have been high but the amount of overall fat mobilization was low.

Differences in antilipolytic responsiveness to insulin were mainly due to stage of lactation. The clearance rate of NEFA from the bloodstream was consistently decreased at 560 DIM irrespective of diet, indicating decreased responsiveness of adipose tissue to insulin and reflecting either decreased rates of re-esterification of fatty acids or increased rates of lipolysis. Therefore, cows may be less sensitive to the action of insulin in terms of the inhibition of lipolysis or the stimulation of lipogenesis. High plasma concentrations of NEFA are associated with decreased responsiveness to insulin (Pires et al., 2007). However, the low concentration of NEFA in the blood itself might have acted as a barrier to further reduction in plasma NEFA in response to the ITT, given that it is not possible to reduce the plasma NEFA concentration to zero. The rate at which NEFA appeared in the bloodstream (CR 50-120) following the nadir was greater at 100 DIM than in later stages of lactation, indicating a more rapid recovery from the effects of severe hypoglycemia at this stage of lactation due to variation in counter-regulatory endocrine responses. This supports the first hypothesis and indicates an increased propensity for cows to release fatty acids into the bloodstream, rather than storing them in adipose tissue, in the earlier stages of lactation.

We detected small effects of diet and interactions between diet and DIM on the responses of both glucose and NEFA to the ITT. The clearance rate of NEFA was greatest at 250 DIM in CON cows but greatest at 100 DIM in GRN cows. Also, greater rates of NEFA re-entry to the bloodstream (NEFA CR 50-120 min) indicated greater lipolytic activity at 100 DIM in both the CON and GRN treatments, but also at 560 DIM in the CON treatment only. The greater plasma glucose and NEFA concentrations in the recovery phase during the first $300 \mathrm{~d}$ compared with the second $300 \mathrm{~d}$, and in GRN cows compared with CON cows, is consistent with variation in counter-regulatory responses to the ITT. Thus, we reject our second hypothesis that increasing the amount of cereal grain in the diet would not affect the response of plasma glucose or NEFA to the ITT. However, it is unclear whether these differences are a result of dietary treatment, milk yield potential, or a combination of both. 
Counter-regulatory responses to the hypoglycemia induced by the ITT could include the release of glucagon, epinephrine, or cortisol that act to counter the actions of insulin. These hormones serve to increase blood glucose and NEFA concentrations overall and promote a short-term state of catabolism. Marett et al. (2014) showed that plasma growth hormone concentrations were greater throughout an extended lactation in cows fed a pasture-based diet plus $1 \mathrm{~kg}$ of grain compared with cows fed a further $5 \mathrm{~kg}$ of grain. Sechen et al. (1990) showed that cows treated with bST had elevated plasma NEFA and glycerol concentrations and were more responsive to epinephrine than untreated cows. An increase in the responsiveness to epinephrine in the CON cows could explain the increased recovery concentrations of plasma glucose and NEFA. Furthermore, recovery levels of NEFA surpassed basal concentrations at all stages of lactation following the ITT and suggest that counter-regulatory mechanisms are involved after the more-pronounced hypoglycemia observed during the ITT rather than IVGTT reported previously (Marett et al., 2015). Further investigation into the counter-regulation of blood glucose and fatty acid concentrations associated with varying planes of nutrition and at varying stages of lactation would be worthwhile.

\section{CONCLUSIONS}

The responsiveness of insulin-dependent tissues is implicated in the regulation of nutrient partitioning toward milk production during an extended lactation. It is unclear whether the primary driver of peripheral tissue insulin responsiveness is increased dietary intake or the individual cow's ability to produce increased amounts of milk in extended lactations beyond 300 DIM. Responsiveness to insulin was varied in terms of glucose versus fatty acid metabolism, indicating differential responses to insulin in skeletal muscle and adipose tissue. The results suggest that the mechanisms for glucose disposal are relatively fixed in their responsiveness to insulin but that the rate of adipose tissue metabolism differs in its responsiveness to insulin in lactations of up to (and possibly longer than) $560 \mathrm{~d}$. Understanding the hormonal and metabolic regulation of insulin sensitivity and responsiveness with respect to milk yield and nutrient partitioning during lactation is important to developing nutritional strategies for cows to sustain extended lactations. The homeorhetic partitioning of nutrients, changing concentrations of plasma hormones, local feedback systems, and availability and sensitivity of tissue receptors all play a role in determining an individual cow's ability to sustain an extended lactation.

\section{ACKNOWLEDGMENTS}

The authors thank Kristy DiGiacomo, Di Mapleson, Greg Morris, Tony Hookey, Alan McDonald, and the technical and farm staff (DEDJTR, Ellinbank, Australia) for their assistance with sampling and cow husbandry. This work was financially supported by the Geoffrey Gardiner Dairy Foundation (Melbourne, Australia), the University of Melbourne (Melbourne, Australia), and DEDJTR, Victoria.

\section{REFERENCES}

Auldist, M. J., G. N. O'Brien, D. J. Cole, K. L. Macmillan, and C. Grainger. 2007. Effects of varying lactation length on milk production capacity of cows in pasture-based dairying systems. J. Dairy Sci. 90:3234-3241. https://doi.org/10.3168/jds.2006-683.

Baird, D. B. 1994. The design of experiments with covariates. PhD Thesis. University of Otago, Otago, New Zealand.

Bauman, D. E., and W. B. Currie. 1980. Partitioning of nutrients during pregnancy and lactation: A review of mechanisms involving homeostasis and homeorhesis. J. Dairy Sci. 63:1514-1529. https:// doi.org/10.3168/jds.S0022-0302(80)83111-0.

Bell, A. W., and D. E. Bauman. 1997. Adaptations of glucose metabolism during pregnancy and lactation. J. Mammary Gland Biol Neoplasia 2:265-278. https://doi.org/10.1023/A:1026336505343.

Bergman, E. N., S. S. Reulein, and R. E. Corlett. 1989. Effects of obesity on insulin sensitivity and responsiveness in sheep. Am. J. Physiol. 257:E772-E781.

Blum, J. W., P. Kunz, H. Leuenberger, K. Gautschi, and M. Keller. 1983. Thyroid hormones, blood plasma metabolites and haematological parameters in relation to milk yield in dairy cows. Anim. Sci. 36:93-104. https://doi.org/10.1017/S0003356100039982.

Brockman, R. P., and B. Laarveld. 1986. Hormonal regulation of metabolism in ruminants: A review. Livest. Prod. Sci. 14:313-334. https://doi.org/10.1016/0301-6226(86)90012-6.

Busato, A., D. Faissler, U. Kupfer, and J. W. Blum. 2002. Body condition score in dairy cows; associations with metabolic and endocrine changes in healthy dairy cows. J. Vet. Med. A Physiol Pathol. Clin. Med. 49:455-460. https://doi.org/10.1046/j.14390442.2002.00476.x.

Chagas, L. M., B. A. Clark, F. M. Rhodes, D. Blache, E. S. Kolver, and G. A. Verkerk. 2003. Metabolic responses to glucose challenge in New Zealand and overseas Holstein-Friesian dairy cows. Proc. N.Z. Soc. Anim. Prod. 63:31-34.

Chagas, L. M., M. C. Lucy, P. J. Back, D. Blache, J. M. Lee, P. J. S. Gore, A. J. Sheahan, and J. R. Roche. 2009. Insulin resistance in divergent strains of Holstein-Friesian dairy cows offered fresh pasture and increasing amounts of concentrate in early lactation. J. Dairy Sci. 92:216-222. https://doi.org/10.3168/jds.2008-1329.

Collier, R. J., J. P. McNamara, C. R. Wallace, and M. H. Dehoff. 1984 A review of endocrine regulation of metabolism during lactation. J. Anim. Sci. 59:498-510.

Cronje, P. B. 2000. Nutrient-gene interactions: Future potential applications. Pages 409-422 in Ruminant Physiology: Digestion, Metabolism, Growth and Reproduction. P. B. Cronje, ed. CAB International, New York, NY.

De Koster, J., M. Hostens, K. Hermans, W. Van den Broeck, and G. Opsomer. 2016. Validation of different measures of insulin sensitivity of glucose metabolism in dairy cows using the hyperinsulinemic euglycemic clamp test as the gold standard. Domest. Anim. Endocrinol. 57:117-126. https://doi.org/10.1016/j domaniend.2016.06.004.

Debras, E., J. Grizard, E. Aina, S. Tesseraud, C. Champredon, and M. Arnal. 1989. Insulin sensitivity and responsiveness during lactation and dry period in goats. Am. J. Physiol. 256:E295-E302.

Delany, K. K., K. L. Macmillan, C. Grainger, P. C. Thomson, D. Blache, K. R. Nicholas, and M. J. Auldist. 2010. Blood plasma 
concentrations of metabolic hormones and glucose during extended lactation in grazing cows or cows fed a total mixed ration. J. Dairy Sci. 93:5913-5920. https://doi.org/10.3168/jds.2010-3609.

Denbow, C. J., K. S. Perera, F. C. Gwazdauskas, R. M. Akers, R. E. Pearson, and M. L. McGilliard. 1986. Effect of season and stage of lactation on plasma insulin and glucose following glucose injection in Holstein cattle. J. Dairy Sci. 69:211-216. https://doi. org/10.3168/jds.S0022-0302(86)80388-5.

Dhiman, T. R., J. Kleinmans, N. J. Tessmann, H. D. Radloff, P. Van Evert, and L. D. Satter. 1991. Effect of dietary forage:grain ratio on blood constituents in dairy cows. J. Dairy Sci. 74:2691-2695. https://doi.org/10.3168/jds.S0022-0302(91)78447-6.

Dunshea, F. R., A. W. Bell, and T. E. Trigg. 1990. Non-esterified fatty acid and glycerol kinetics and fatty acid re-esterification in goats during early lactation. Br. J. Nutr. 64:133-145. https://doi. org/10.1079/BJN19900016.

Dunshea, F. R., and D. N. D'Souza. 2003. Fat deposition and metabolism in the pig. Pages 127-150 in Proc. Manipulating Pig Production. Australasian Pig Science Association, Fremantle, Western Australia.

Evans, E., J. G. Buchanan-Smith, G. K. MacLeod, and J. B. Stone. 1975. Glucose metabolism in cows fed low-and high-roughage diets. J. Dairy Sci. 58:672-677. https://doi.org/10.3168/jds.S00220302(75)84626-1.

Grainger, C., M. J. Auldist, G. O'Brien, K. L. Macmillan, and C. Culley. 2009. Effect of type of diet and energy intake on milk production of Holstein-Friesian cows with extended lactations. J. Dairy Sci. 92:1479-1492. https://doi.org/10.3168/jds.2008-1530.

Holtenius, K., S. Agenas, C. Delavaud, and Y. Chilliard. 2003. Effects of feeding intensity during the dry period 2. Metabolic and hormonal responses. J. Dairy Sci. 86:883-891. https://doi. org/10.3168/jds.S0022-0302(03)73671-6.

Jenny, B. F., and C. E. Polan. 1975. Postprandial blood glucose and insulin in cows fed high grain. J. Dairy Sci. 58:512-514. https:// doi.org/10.3168/jds.S0022-0302(75)84599-1.

Johnson, M. M., and J. P. Peters. 1993. Technical note: An improved method to quantify nonesterified fatty acids in bovine plasma. J. Anim. Sci. 71:753-756.

Kaneko, J. J. 1997. Carbohydrate metabolism and its diseases. Pages 45-81 in Clinical Biochemistry of Domestic Animals. J. J. Kaneko, ed. Academic Press, San Diego, CA.

Kolver, E. S., J. R. Roche, C. R. Burke, J. K. Kay, and P. W. Aspin. 2007. Extending lactation in pasture-based dairy cows: I. Genotype and diet effect on milk production. J. Dairy Sci. 90:55185530. https://doi.org/10.3168/jds.2007-0324.

Marett, L. C., M. J. Auldist, C. Grainger, W. J. Wales, D. Blache, K. L. Macmillan, and B. J. Leury. 2011. Temporal changes in plasma concentrations of hormones and metabolites in pasture-fed dairy cows during extended lactation. J. Dairy Sci. 94:5017-5026. https://doi.org/10.3168/jds.2011-4272.

Marett, L. C., M. J. Auldist, P. J. Moate, W. J. Wales, K. L. Macmillan, F. R. Dunshea, and B. J. Leury. 2015. Response of plasma glucose, insulin, and nonesterified fatty acids to intravenous glucose tolerance tests in dairy cows during a 670-day lactation. J. Dairy Sci. 98:179-189. https://doi.org/10.3168/jds.2014-8205.
Marett, L. C., M. J. Auldist, W. J. Wales, K. L. Macmillan, K. DiGiacomo, and B. J. Leury. 2014. Evaluation of growth hormone response to insulin-induced hypoglycaemia in dairy cattle during a 670-day lactation. Anim. Prod. Sci. 54:1323-1327. https://doi. org/10.1071/AN14224.

McClary, D. G., J. L. Sartin, R. J. Kemppainen, and J. C. Williams. 1988. Insulin and growth hormone responses to glucose infusion in mature and first-lactation dairy cows. Am. J. Vet. Res. 49:17021704.

Pires, J. A. A., A. H. Souza, and R. R. Grummer. 2007. Induction of hyperlipidemia by intravenous infusion of tallow emulsion causes insulin resistance in Holstein cows. J. Dairy Sci. 90:2735-2744. https://doi.org/10.3168/jds.2006-759.

Prior, R. L., and R. K. Christenson. 1978. Insulin and glucose effects on glucose metabolism in pregnant and nonpregnant ewes. J. Anim. Sci. 46:201-210.

Reist, M., D. Erdin, D. von Euw, K. Tscheumperlin, H. Leuenberger, Y. Chilliard, H. M. Hammon, C. Morel, C. Philipona, Y. Zbinden, N. Keunzi, and J. W. Blum. 2002. Estimation of energy balance at the individual and herd level using blood and milk traits in high-yielding dairy cows. J. Dairy Sci. 85:3314-3327. https://doi. org/10.3168/jds.S0022-0302(02)74420-2.

Ronge, H., J. W. Blum, C. Clement, F. Jans, H. Leuenberger, and H. Binder. 1988. Somatomedin C in dairy cows related to energy balance and protein supply and to milk production. Anim. Prod. 47:165-183. https://doi.org/10.1017/S000335610000324X.

Sano, H., S. Narahara, T. Kondo, A. Takahashi, and Y. Terashima. 1993. Insulin responsiveness to glucose and tissue responsiveness to insulin during lactation in dairy cows. Domest. Anim. Endocrinol. 10:191-197. https://doi.org/10.1016/0739-7240(93)90023-5.

Sartin, J. L., K. A. Cummins, R. J. Kemppainen, D. N. Marple, C. H. Rahe, and J. C. Williams. 1985. Glucagon, insulin, and growth hormone responses to glucose infusion in lactating dairy cows. Am. J. Physiol. 248:E108-E114.

Schoenberg, K. M., R. M. Erhardt, and T. R. Overton. 2012. Effects of plane of nutrition and feed deprivation on insulin responses in dairy cattle during late gestation. J. Dairy Sci. 95:670-682. https://doi.org/10.3168/jds.2011-4529.

Sechen, S. J., F. R. Dunshea, and D. E. Bauman. 1990. Somatotropin in lactating cows: Effect on response to epinephrine and insulin. Am. J. Physiol. 258:E582-E588.

Sorensen, A., and C. H. Knight. 2002. Endocrine profiles of cows undergoing extended lactation in relation to the control of lactation persistency. Domest. Anim. Endocrinol. 23:111-123. https://doi. org/10.1016/S0739-7240(02)00150-9.

Tindal, J. S., G. S. Knaggs, I. C. Hart, and L. A. Blake. 1978. Release of growth hormone in lactating and non-lactating goats in relation to behaviour, stages of sleep, electroencephalograms, environmental stimuli and levels of prolactin, insulin, glucose and free fatty acids in the circulation. J. Endocrinol. 76:333-346. http://dx.doi. org/https://doi.org/10.1677/joe.0.0760333.

Vernon, R. G., and C. M. Pond. 1997. Adaptations of maternal adipose tissue to lactation. J. Mammary Gland Biol. Neoplasia 2:231-241. https://doi.org/10.1023/A:1026380220364. 